\title{
ITINERARIO DE UNA ARQUITECTURA POÉTICA: LAS CASAS DE PABLO NERUDA
}

\author{
a John Wiginns \\ a José Daniel Wiggins
}

Con el advenimiento del gobierno democrático de Patricio Alwyn en 1990, finaliza un legado de terror y despotismo de aproximadamente diecisiete años en Chile. La censura y la autocensura que tanto modificaron el espíritu creativo de la nación se encuentra lleno de energía y apertura y uno de los logros de mayor envergadura después de la derrota de Pinochet consiste en las casas de Pablo Neruda, abiertas después de una clausura obligatoria por la dictadura militar.

Pablo Neruda fue un poeta coleccionista de antigüedades, de botellas azules de caracoles y pipas; también de casas que con su presencia se convirtieron en espacios de poesía con coloridos luminosos y siempre dispuestas al juego. La casa en Isla Negra, comenzada en 1938, habitat que Neruda amó por sobre todas las cosas ya que gran parte de su obra nació en ella, fue abierta meses después de la derrota de Pinochet aproximadamente en septiembre de 1992, mes de la patria y los aromos, pequeños arbustos amarillos que pueblan la primavera chilena.

La casa de Santiago, llamada la Chascona porque tenía un techo de paja desordenado e intrépido, también fue abierta un mes después de la de Isla Negra. Este enero de 1992, una de las casas más queridas de Neruda, la Sebastiana en Valparaíso, abrió sus puertas, trepó hasta el aire más puro del cielo y rindió una memoria siempre presente al legado del poeta arquitecto.

Recién ahora, los niños de Chile, los adolescentes, los adultos nostálgicos y siempre enamorados del creador, de los XX poemas y una canción desesperada pueden visitar los lugares que el poeta amaba, acercarse a ellos, jugar con los mascarones de proa y llamarlos por sus nombres. La poesía y la democracia florecen nuevamente en mi país y las casas de Pablo Neruda se llenan de docas y flores silvestres. Avancemos en este texto a conocer a dos de ellas.

\section{La Casa de Isla Negra}

La casa de Isla Negra fue la primera y la más querida por el poeta. Empezó su construcción alrededor de los 30 y por fin pudo casi terminarla en los 50 con las regalías de su derecho de autor. Los cuartos de esta casa, son más parecidos a la magia que a las 
texturas nobles de las maderas. Así Isla Negra creció junto a las enredaderas, junto al viento y al inmenso Océano Pacífico, guardián protector de tanta maravilla.

Cuando Neruda llegó a Isla Negra, él mismo dice que no había ni veraneantes, ni ricos.

Yo funde Isla Negra con el doctor Raul Bulnes y el capitan de navio Eladio Sobrino. Cuando llegamos no habra ricos, ni servicios higienicos, ni electricidad, ni arboles. Yo los plante, junto con ellos. Y después de treinta años de amar a la Isla, de mis libros escritos en ella, del escribir Carlos Rozas Larrain sobre Isla Negra, de dar su nombre a mi Memorial, de convertirla en sello literario. ${ }^{1}$

La casa de Isla Negra se convierte en el habitat por excelencia del poeta, sitio para el ensueño como también para las colecciones de cuanta cosa imaginaba. También para la calidez compartida entre los amigos que siempre llegaban a estas regiones en busca de poesía, buen vino y amistad.

No los escribt en la techedumbre por grandiosos, sino por compañeros.

Rojas Giménez, el trashumante, el noctumo, traspasado por los adioses, muerto de alegría, palomero, loco de la sombra.

Joaquin Cifuentes, cuyos tercetos rodaban como piedras del río.

Federico, que me hacia reír como nadiey que nos enlutó a todos por un siglo.

Paul Eluard, cuyos ojos color de nomeolvides me parece que siguen celestes y que guardan su fuerza azul bajo la tierra.

Miguel Hernandez, silbándome a manera de ruiseñor desde los árboles de la calle de la Princesa antes de que los presidios atraparon a mi ruiseñor.

Nazim, aeda rumoroso, caballero valiente, compañero.

¿Porquése fueron tan pronto? Sus nombres no resbalaran de las vigas. Cada uno de ellos fue una victoria. Juntos fueron para mi toda la luz. Ahora, una pequeña antología de mis dolores. ${ }^{2}$

En el invierno chileno, una vez que la isla queda tranquila, sin veraneantes y su desolada belleza invita a largas caminatas y reflexiones. En el mes de marzo, cuando los últimos resquicios del verano se perfilan a través de días luminosos, cuando es posible entrar a la casa de Don Pablo. Ya se ha abierto el candado de cobre y las puertas de madera se abren serenas y victoriosas. El patio de la casa está tapizado de unos frondosos pinos verdes con un olor a tierras del sur y a una fragancia inconfundible e inolvidable. Una enorme locomotora roja aparece en el medio del jardín como también una campana que anuncia el

1 Sara Vial, Neruda en Valparaíso, Ediciones Universitarias de Valparaíso, Santiago, 1983, p. 115.

2 Pablo Neruda, The housse of Sand, traducido por Dennis Maloney y Clark Zlotchew, Ediciones Milkweed, Minneapolis, 1990 , p. 50. 
ritmo de las estaciones y el presagio del tiempo. El mar nos rodea, nos acompaña y celebra nuestra presencia. Somos seres curiosos anodados ante una belleza atávica y magnífica. El mar como dice Neruda pareciera haberse reído de nosotros sus descubridores:

El viejo océano descubrío a carcajadas a sus descubridores. Sostuvo sobre su movimiento maories inconstantes, fijianos que se devoraban, samoas comedores de nenúfares, locos de Rapa Nui que construian estatuas, inocentes de Tahiti astutos de las islas, y luego vizcainos, portugueses, extremeños con espadas, castellanos con cruces, ingleses con talegas, andaluces con guitarra, holandeses errantes. Yque?

Continuamos recorriendo estos laberintos luminosos, asombrados, y en nuestro caminar en puntillas entramos a esta casa llena de pasadizos, de rincones para el amor, de piezas clandestinas donde aparecen grandes colecciones de cajas, de pipas, de libros y de mariposas. En una misteriosa pieza al fondo, un gran caballo traído de Temuco, caballo de cerámica y cera, caballo para jugar y crear. Porque para el poeta el juego es la vida:

En mi casa he reunido juguetes pequeños o grandes; sin los cuales no podria vivir, escribio en sus Memorias. El niño que no juega no es niño, pero el hombre que no juega perdio para siempre al nin̄o que vivia en ély que le haria mucha falta. ${ }^{4}$

Extasiados, continuamos la travesía por la casa. Nosotros también pretendemos ser navegantes en tierra firme y nos preguntamos, ¿Cómo nació esta casa?

La casa... No sé cuándo nacio... Era a media tarde, llegamos a
caballo por aquellas soledades... Don Eladio iba delante, vadeando el
estero de Cordoba que se habia crecido... Por primera vez senti como
una punzada este olor a invierno marino, mezcla de boldo y arena
salada, algas y cardos. 5

En el centro de la vivienda, el mar desparramado y presente, los enormes ventanales presagian maremotos y sargazos, alrededor de las ventanas, enormes botellas azules que reflejan el ritmo y la felicidad de los días. Todo parece estar hechizado en Isla Negra, todo parece ser transportado de y hacia otros tiempos pero por sobre todas las cosas, los mascarones de proa contemplándonos.

En mi niñez, mi madre me solía contar de la María Celeste, que ella también la había visto llorar en los días de sal y tristeza. Ahora yo me acerco a María Celeste pero no parece un mascarón de proa lejano y trasplantado, todo lo contrario, es tan bella porque desde siempre perteneció a estas cosas del Pacífico.

\footnotetext{
3 Neruda, p. 22.

4 Vial, p. 31.

5 Neruda, p. 42.
} 
Alain y yo la sacamos del mercado de las Pulgas donde yacia bajo siete capas del olvido. En verdad costaba trabajo divisarla entre camas desmanteladas, fierros torcidos. La llevamos en aquel coche de Alain, encima, amarrada, y luego en un cajon, tardando mucho, llego a Puerto San Antonio. Solimano la rescato de la aduana, invicta, y me la trajo hasta Isla Negra.

Pero ya la habia olvidado. O tal vez conservé el recuerdo de aquella aparicion polvorienta entre la 'ferraille'. Solo cuando destaparon la pequeña caja sentimos el asombro de su imponderable presencia.

Fue hecha de madera oscura y tan perfectamente dulce! Y se la lleva el viento que levanta su tünica! $Y$ entre la juventud de sus senos un broche le resguarda el escote. Tiene dos ojos ansiosos en la cabeza levantada contra el aire. Durante el largo invierno de Isla Negra algunas misteriosas lagrimas caen de sus ojos de cristal y se quedan por sus mejillas, sin caer. La humedad concentrada, dicen los escepticistas. Un milagro, digo yo, con respeto. No le seco sus lagrimas, que no son muchas, porque me acostumbré a su llanto, tan escondido y recatado, como si no debiera advertirse. Y luego pasan los meses fríos, llega el sol, y el dulce rostro de María Celeste sonríe suave como la primavera.

Pero, ¿por qué llora? ${ }^{6}$

Estamos ahora detenidos frente al gran océano Pacífico, es verdad que tal vez se salía del mapa:

El Océano Pactfico se salía del mapa. No habia donde ponerlo. Era tan grande, desordenado y azul que no cabía en ninguna parte. Por eso lo dejaron frente a mi ventana.

Los humanistas se preocuparon de los pequeños hombres que devoro en sus años:

No cuentan.

Ni aquel galeón cargado de cinamomo y pimienta que lo perfumo en el naufragio,

No.

Ni la embarcación de los descubridores que rodó con sus hambrientos, fragil como una cuna desmantelada en el abismo.

No.

El hombre en el océano se disvuelve como un ramo de sal, Y el agua no lo sabe. ${ }^{7}$ 
Más allá del mar se encuentra la arena delicada, suave, a veces oscura y misteriosa. La arena donde las huellas de los caminantes dibujan el ritmo del amor y de la soledad. Desde muy niña cuando mi madre y yo íbamos a caminar a Isla Negra distinguíamos la enorme figura de don Pablo con un auténtico poncho traido de la remota araucaria haciendo piruetas y gestos de felicidad mientras caminaba turbado, meditando tras la arena de Isla Negra:

Estas arenas de granito amarillo son privativas, insuperables, (la arena negra se adhiere a la piel, al vestido, son impalpables e intrusas). Las arenas doradas de Isla negra están hechas como pequenísimos peñascos como si procedieran de un planeta demolido, que ardió lejos, alla ariba, remoto y amarillo.

Todo el mundo cruza la ribera arenosa y agachándose y buscando, removiendo, tanto que alguien llamó a esta costa "la Isla de las cosas Perdidas".

El Océano es incesante proveedor de tablones carcomidos, bolas de vidrio verde o flotadores de corcho, fragmentos de botella ennoblecidos por el oleaje, detritus de cangrejos, caracolas, lapas, objetos devorados, envejecidos por la presión y la insistencia. Existe entre espinas quebrizadas o erizos minúsculos o patas de jaiva morada, el serpentino cochayuyo, nutricion de los pobres, alga interminable y redondo como una anguila, que resbala y brilla, sacudida aún en la arena por la ola reticente, por el océano que la persigue. Ya se sabe que esta planta del mar es la mas larga del planeta creciendo hasta cuatrocientos metros, prendida como un titanico chupón al roquerío, sustentándolo con una division de flotadores que sostienen la cabellera del alga macrocritis con millares de tetitas de ámbar. Y como en el territorio andino vuela al condory sobre el mar chileno se reúnen planeando todas las familias del albatros y como el cachalote o ballena dentada se sumergio en nuestras aguas y aqui sobrevive, somos una pequeña patria de alas muy grandes, de cabelleras muy largas sacudidas por el gran océano, de presencias sombrías en las bodegas del mar. ${ }^{8}$

La casa de Isla Negra, sitial amado y construido con la exquisita sabiduría de un poeta coleccionista de lo verosímil y de lo inverosímil, desafía todas las leyes de la lógica arquitectónica, la de simetría de los espacios. Pienso que es una casa para la poesía y la felicidad. Llegar a ella es participar en los laberintos de lo ensoñado de una belleza que tan sólo puede ser nombrada con los nombres de la poesía.

Nos alejamos de Isla Negra, el sonido nostálgico de las campanas, la locomotora rojiza anunciando la llegada de algunos visitantes invisibles, la tarde en Isla Negra con sus colores, 
malvas marinos y bermellones. También nos despedimos del mar, de la María Celeste y de las ágatas que reposan en la arena como melenas marinas.

Pero de donde vienen a mis manos sestas agatas! Cada mañana aparecen frente a mi puerta, y es la arrebatiña auroral, pues algún extraviado pastor de tierra adentro, o Gonzáles Vera, o Lina o María pueden disputar pequeñas piedras translúcidas a los Yankas, mariscadores de oficio, que, al pie del mar, acechan la mercaderí, $y$ se creen con derecho a cuanto bota la ola.

Lo cierto es que ellos me madrugaron siempre y he aqui una vez más el tesoro que me manda el mar, solo en sus manos, a tanto la piedra o las cien piedras o el kilo o el tonel.

Y en la mano las misteriosas gotas de luz redonda, color de la miel o de ostra, parecidas a uvas que se petrificaron para caber en los versos de Gentil de Espinosa, suavemente espolvoreados por alguna deidad cenicienta, horadadas a veces en su centro por algín aguijon de oro, socavadas como por la más diminuta de las olas: agatas de Isla Negra, neblinosas o celestes, suavemente carmíneas o verdiverdes, $o$ avioletadas o rojizas o ensaladas por dentro como racimos moscateles: y a menudo estaticas de transparencia, abiertas a la luz, entregadas por el panal del océano al albedrío de cristal: a la pura pureza. 9

\section{La Sebastiana}

Este 20 de enero de 1992 se inauguró en Valparaíso la Sebastiana, otra de las casas del poeta que también se mantenía cerrada por decreto militar. Si la casa de Isla Negra representa lo marino, los orígenes, el encuentro con la sal y el agua, los comienzos del río, la Sebastiana representa el aire y el cielo, es decir, el mar desde la altura. No es extraño que Neruda haya escogido este puerto desordenado excéntrico y colorido para vivir. En numerosas ocasiones, cuando le preguntaban a Neruda si era de Chile, el respondía que no, que era de Valparaíso.

Sara Vial, la insigne poeta de Valparaíso, afirma lo siguiente cuando habla de la Sebastiana:

Es preciso amar la gaviotas para hallarla y comprender los barcos, para quedarse en ella. Para llegar a su mundo lunar, se atraviesa por susurrantes cortinas de mostacillas multicolores, bocas de viejos fonografos, caja de música y antiguos grabados que ascienden con veleros, caballos y pajaros. Una policromía de bermellones, azules o azafranes por fuera y, por dentro, el mundo de un anticuario poeta 
que crea sus casas como juguetes encantados, para alegrar a sus amigos, a su corazbn, o a los niños que no llegaban a jugar aun con las bolas de vidrio llenas de flores y mariposas o el caballito de carrusel, oscilando frente a la chimenea blanca. ${ }^{10}$

Para llegar a la Sebastiana hay que desplazarse a través del famoso camino de cintura, colección de curvas peligrosas pero exquisitas, que viajan, que gravitan por numerosos cerros con nombre de peligro y poesía: Cordillera, Cerro Alegre - Mariposa.

Escamoteada tras un teatro, con una enorme pared azul en un callejón casi invisible con vecinos humildes y generosos, ahí está la Sebastiana muy cerca del cielo. Es una casa que jamás fue terminada lo que acentúa su belleza y su grato misterio. En un septiembre del 63 Neruda la inagura. En el mes de la patria de los volantines y de las flores que crecen silvestres y mágicas:

Una rama de aromo, una mimosa, fragante sol del entumido invierno, compré en la Ferie de Valparaíso. ${ }^{11}$

Llegamos muy temprano a la Sebastiana, somos los primeros en entrar a la casa de los ensueños. A mi hijo de cuatro años ya le fascinan estas extrañas escaleras, el mismo Neruda dice lo siguiente al respecto en una prosa publicada en Alemania:

Escaleras que a medio camino dieron nacimiento a un cardo de flores púrpureas.

Escaleras que subio el marinero que volvía de Asia y que encontro en su casa una nueva sonrisa o una ausencia temible!

Escaleras por las que bajo como un meteoro negro un borracho que caía!

Escaleras por donde sube el sol para dar amor a las colinas!

Si caminamos todas las escaleras de Valparatso habremos dado la vuelta al mundo.

Nosotros nos dirigimos rumbo al cielo, llegamos a la sala, el rostro de Valparaíso aparece en su fulminante belleza con los barcos coloridos son el sonido a viajes y a nostalgia. Neruda, solo, pasa mucho tiempo ensimismado y detenido en el movimiento de los buques y en la noche los ve cabalgar iluminados, llenos de brujería y magia. El mismo, al hablar del puerto y sus colores, nos dice:

Porque, de todos modos, las casas se hicieron colores y en la misma construcción se juntaron el maranto a el amarillo, el carmín y el cobalto, el verde y el purpúreo. Asi cumplio Valparaíso su misión de puerto verdadero, de navio encallaso, pero viviente; de nave con sus

10 Vial, pp. 9-10.

11 Vial, p. 14.

12 Vial, p. 15. 
banderas al viento. Yel viento del Océano Mayor merecía una ciudad de banderas. ${ }^{13}$

De todas las ciudades chilenas, Neruda guardaba para Valparaíso un amor especial y escribió versos dedicados a este puerto de ensueño como de una arquitectura desbordada:

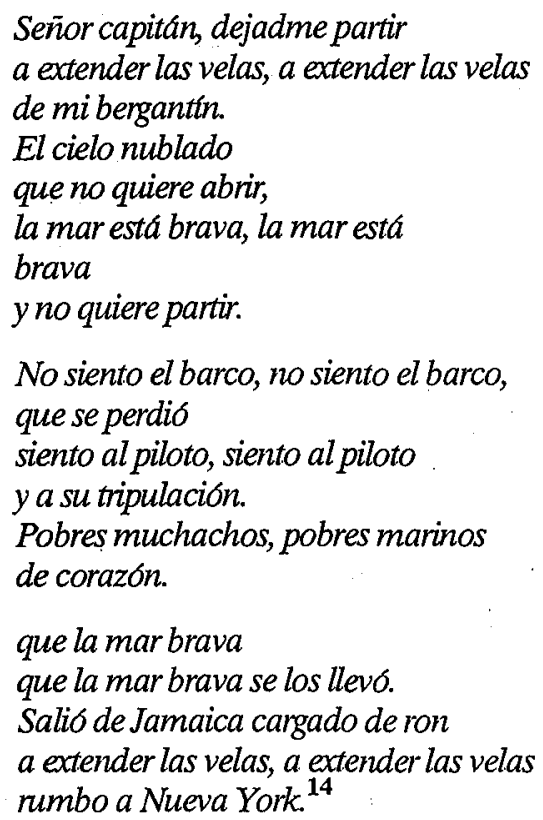

Continuamos el ascenso hacia el último piso, en la Sebastiana hay enormes claraboyas y ventanas, las gaviotas se confunden con los peces extraviados, todo es azul, malva y rosa. En el último piso, la cama de fierro de Neruda en un ángulo perfecto siempre en dirección al mar, como si fuera a lanzarse hacia esas aguas turbias e iluminadas. En Isla Negra, también la cama del poeta pareciera siempre dispuesta a flotar hacia el mar e integrarse de una sola vez con el origen del agua.

Descendemos mareados de dicha y nosotros también Valparaíso nos deslumbra,

Valparaiso oscuro arde en la arena del Pacííico como una ascua fría, como una estrella de mil puntas. Valparaíso me usurpo, me sometio a un dominio, a su disparate: Valparaíso es un montón, es un racimo de casas locas, es un pajaro que cae sobre tu cabeza, es un niño pobre entre los fierros viejos, es una mujer agobiada, es una distancia. Una pareja, una cama, Valparaíso es una escalera y tres cebollas, otra

13 Vial, p. 16.

14 Vial, p. 19. 
escalera que conduce a las nubes, y otra que nos invita a las avidas ajenas, a la intimidad escumidiza que nunca alcanzaremos a compartir sino con los escalones pisados por un millón de pies que pasaron enfundándose en las sábanas del dia Domingo, cuando todo corre escalas amiba, hacia los cerros, hacia las familias numerosas, hacia la pobreza de arriba, pobreza orgullosa y férrea templada en todos combates de tierra y mar. ${ }^{15}$

Una vez más me dirijo al cuarto del ensueño, el catre de bronce es pequeño pero me imagino a Pablo de Neruda y Matilde Urrutia mirando enamorados el zarpazo y la llegada de los barcos, haciendo poemas con las miradas porque en la Sebastiana todo es posible:

Yo construi la casa.

La hice primero de aire.

Luego subi en el aire la bandera

y la deje colgada

del firmamento, de la estrella, de

la claridad y de la oscuridad.

Cemento, hierro y vidrio

eran la fábula,

valian más que el trigo y como el oro,

habta que buscary que vender,

y asi llego un camión:

bajaron sacos

y más sacos,

la torre se agarro a la tierra dura

- pero, no basta, dijo el Constructor,

falta cemento, vidrio, fierro, puertas,

y no dormi en la noche.

Pero crecia,

crectan las ventanas

y con poco,

con pegarle el papel y trabajar

$y$ arremeterle con rodilla y hombre

iba a crecer hasta llegar a ser,

hasta poder mirar por la ventana,

y parecía que con tanto saco

pudiera tener techo y subiría

y se agarrara, al fin, de la bandera

que aún colgaba del cielo sus colores. ${ }^{16}$

Vial, p. 16. 
Las casas de Neruda han vuelto de abrirse, como se abrió el país de una dictadura dura y siniestra, dándole la bienvenida a los exiliados, a los censurados, refugio a los törturados. Los niños hacen excursiones a Isla Negra y a Valparaíso, se llenan de mar y aire, sobre todo aquellos que nunca han visto el mar. Los jóvenes adolescentes continúan repitiendo los ritos del amor y graban en los troncos corazones y poemas de don Pablo. Todo esto nos hace pensar que la poesía en Chile, en Latinoamérica, florece que aun es posible oír a pescadores recitar los poemas de Neruda, que aun es posible ver a los niños de las escuelas decir con júbilo que irán de paseo a visitar las casas del poeta.

En el gobierno democrático de mi país se abrieron las casas de Neruda, se abrío la poesía y la vida transcurre libremente como los senderos de agua y tierra.

\section{Povzetek}

\section{ITINERAR PESNIŠKE ARHITEKTURE: HIŠE PABLA NERUDE}

Po sedemnajstih letih Pinochetove diktature je čilska kultura ponorno zaživela svobodno. Tako so ponovno odprli očem javnosti zapuščino Pabla Nerude. Sem sodita tudi dve hiši v Isla Negri in La Sebastiana v Valparaísu, kjer je Neruda preživel dobršen del svojega ustvarjalnega obdobja. Tamkajšnja pokrajina, notranjost hiš in številni predmeti, ki jih je pesnik zbiral, so ga vseskozi navdihovali, kar kažejo tudi številne navedbe iz njegovih izvirnih besedil. 